\title{
Cutting Mechanism of Sulfrized Free-Machining Steel
}

\author{
Junsuke Fujiwara $^{1, a}$, Tsubasa Kawazoe ${ }^{1, b}$, Naoki Matsui ${ }^{2, c}$ \\ ${ }^{1}$ Department of Mechanical Engineering, Graduate School of Engineering, Osaka University \\ 2-1, Yamada-oka, Suita, Osaka 565-0871, Japan \\ ${ }^{2}$ Corporate Research and Development Laboratories, Sumitomo Metal Industries Ltd. \\ 1-8, Fusocho, Amagasaki, Hyogo 660-0891, Japan \\ afujiwara@mech.eng.osaka-u.ac.jp, ${ }^{b}$ kawazoe@mapro.mech.eng.osaka-u.ac.jp \\ 'matsui-nok@sumitomometal.co.jp
}

Keyword: Sulflized free-machining steel, Orthogonal cutting, Cutting mechanism, SEM, BUE

\begin{abstract}
Leaded free-machining steel is used in production industry. However the use of the leaded free-machining steel is limited from an environmental problem. So sulfurized free-machining steel, not include lead, has been researched widely. In order to improve the machining performance of the sulfurized free-machining steel, it is necessary to find out the behavior of inclusion. The experiment was carried out to find out the mechanism of the surfurized inclusion on the machinability, using some kinds of materials which were changed the size of the inclusion. In orthogonal cutting, the deformation behaviors of the sulfurized inclusion in the work materials were observed in the vicinity of tool face. Cutting forces were also measured and finished surfaces were observed. Besides, low speed orthogonal cutting in Scanning Electron Microscope (SEM) which was mounted a small cutting device was carried out in order to observe the deformation behavior more microscopically. As a result, it is clear that some inclusions creates voids around them and some broke to several pieces depending on their conditions. Moreover, in order to investigate the formation and growth of BUE, a quick stop experiment was done during turning. As a result, it is clear that the larger inclusions can reduce the formation of BUE.
\end{abstract}

\section{Introduction}

In order to improve efficiency of cutting process in production industry, development of new steel which has good machinablity is desired. The work material which has good surface roughness, easy breakable chip and small tool wear as the good machinablity is expected. And the free-machining steel was developed owning to adding elements which could make the machinablity better. Of all others, leaded free-machining steel and sulfrized free-machining steel are famous. The leaded free-machining steel and sulflized free-machining steel are well used in the production industry. However the use of the leaded free-machining steel is limited from an environmental problem. In order to develop new environmental friendly free-machining steel, it is necessary to find out the behavior of the inclusion in the work material for the improvement of the machining performance.

There are a lot of studies about the behavior of the inclusion in the free-machining steel [1]-[3]. There are some papers about the role of the lead and the manganese sulfide which are the representative inclusions. The $\mathrm{Pb}$ inclusion acts as lubricant and reduces cutting resistance [4]. As the $\mathrm{MnS}$ is harder than steel, the $\mathrm{MnS}$ acts as an internal stress concentration source when the work material reforms into a chip at the cutting edge. And the MnS produced the micro-cracks at shear deformation zone. This is the cause that the shear area became small and reduces the cutting stress [5]. Although these results are almost reasonable, we must think over the role of the inclusion again in order to produce new free-machining steel. The experiment was carried out to find out the mechanism of the sulfrized inclusion on the machinablity, using some kinds of steels which have different size of the inclusion. The observation of the deformation behavior near the cutting edge 
was carried out to investigate the effect of the inclusion in detail.

\section{Experimental method}

In this experiment, two kinds of the sulfrized free-machining steels (Steel A and Steel B) which have different size of the inclusion were used. The steel A contains larger inclusions than the steel B. These sulfrized free-machining steel contain $0.42 \% \mathrm{~S}$, and chemical composition of these materials are almost the same. In an orthogonal cutting at low speed, the cutting forces were measured. The cutting width of the work material was $2 \mathrm{~mm}$. An orthogonal cutting was performed using table feeding system of a horizontal milling machine as shown in Fig. 1. Table 1 shows cutting conditions in orthogonal cutting.

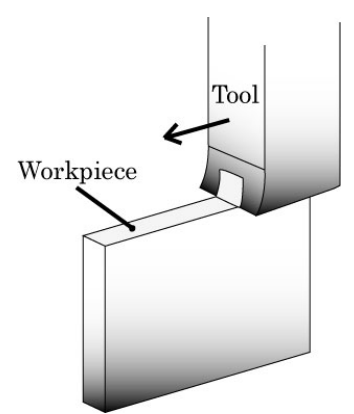

Table 1 Cutting conditions in orthogonal cutting

\begin{tabular}{|c|c|}
\hline Cutting speed & $0.016 \mathrm{~m} / \mathrm{min}$ \\
\hline Depth of cut & $0.1 \mathrm{~mm}$ \\
\hline Tool & SHK 4 \\
\hline Rake angle & $10^{\circ}$ \\
\hline Clearance angle & $17^{\circ}$ \\
\hline
\end{tabular}

Fig. 1 Method of orthogonal cutting

\section{Experimental results and discussions}

The Cutting forces were measured in the orthogonal cutting. These results are shown in Fig. 2. On the whole, the cutting force in the steel A was bigger than that in the steel $\mathrm{B}$. The cutting force in the steel A was more stable than that in the steel B.

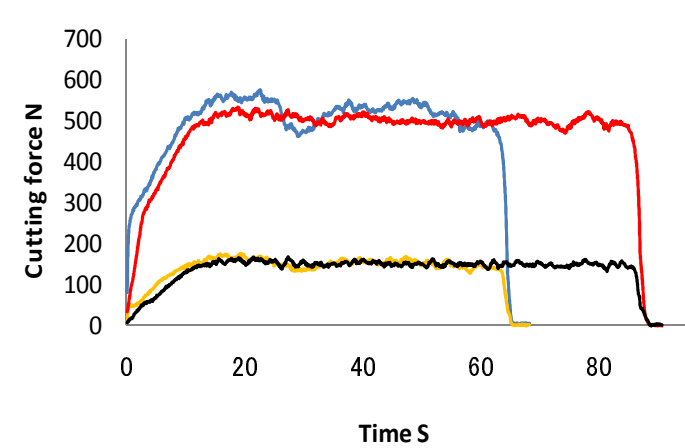

(a) Steel A

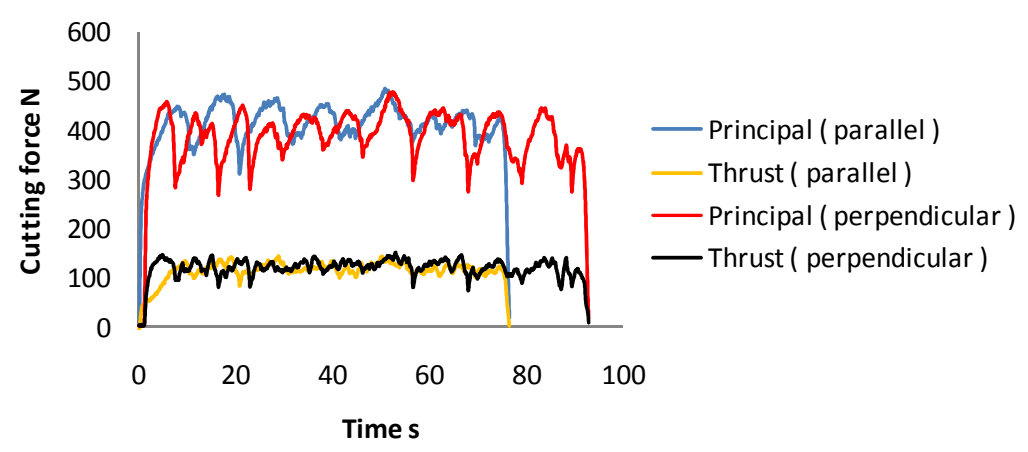

(b) Steel B

Fig. 2 Cutting forces in orthogonal cutting

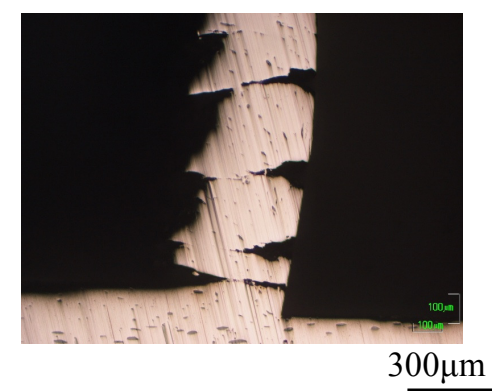

(a) Steel A

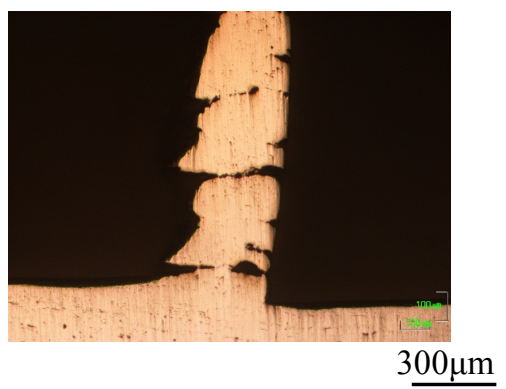

(b) Steel B

Fig. 3 Microphotograph of partially formed chip

In order to investigate the flow state of around the shear zone, a quick stop test was done during orthogonal cutting. Fig. 3 shows the enlarged photographs around the shear zone. In case of the steel A, the large crack parallel to the shear plane was found. In case of steel B, the chip is thin, and 
there are small cracks near the rake face.

Micro-cutting in SEM. A small orthogonal cutting equipment was mounted into the Scanning Electrical Microscope (SEM). The deformation behavior around the shear zone was observed in detail with the SEM. The cutting speed was $0.27 \mathrm{~mm} / \mathrm{s}$ and the depth of cut was $20-50 \mu \mathrm{m}$. Table 2 shows the cutting conditions.

Fig. 4 shows the sequential photographs during cutting of the steel A. The inclusion $\mathrm{MnS}$ which was extended perpendicular to cutting direction can be found. This inclusion turned in counterclockwise and broke to several pieces around the shear zone. These pieces creates voids around them, and flowed to the chip in the direction parallel to the shear plane.

Table 2 Cutting conditions in SEM

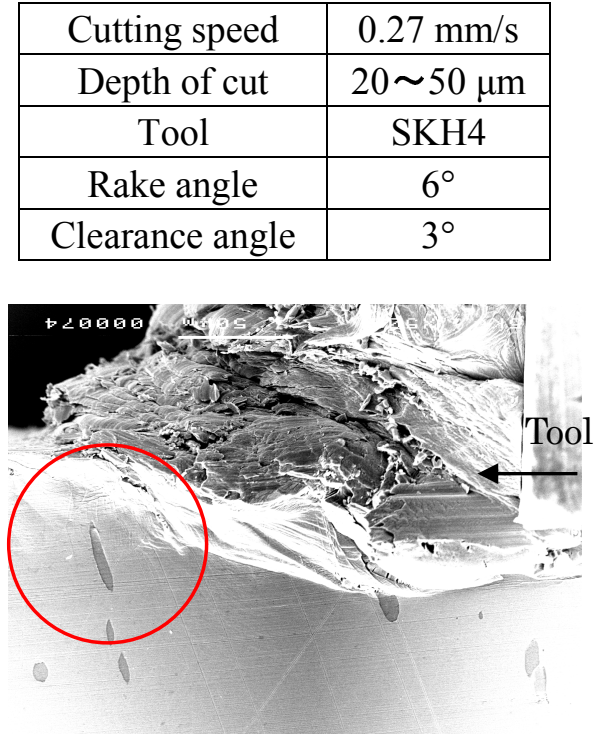

(a)

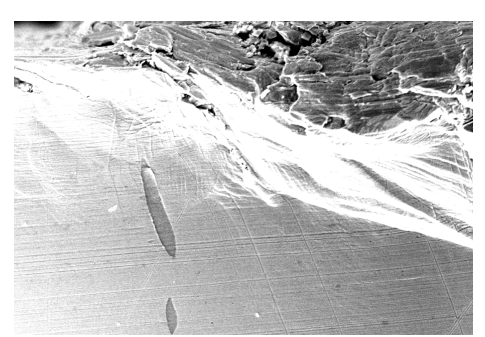

(b)

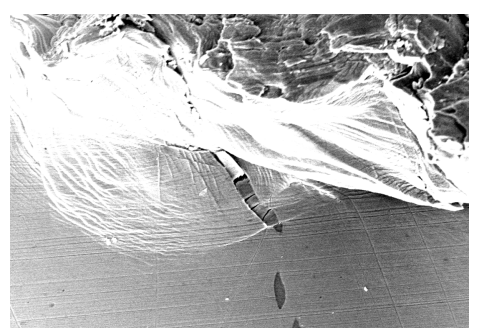

(d)

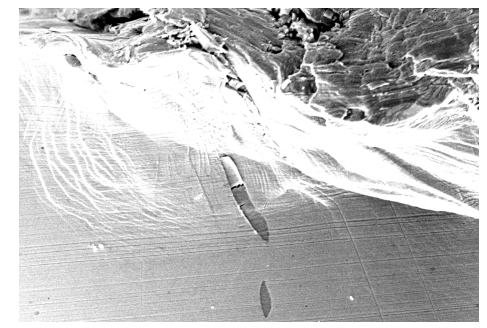

(c)

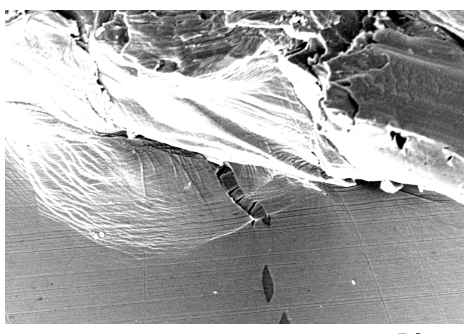

(e)

$50 \mu \mathrm{m}$

Fig. 4 Deformation behavior of inclusion ( steel A )

Fig. 5 shows the sequential photographs during cutting of the steel $\mathrm{B}$. The inclusion of higher aspect ratio than that in the steel A can be found. This inclusion broke into smaller pieces than that in the steel A. these pieces creates very small voids between them. The inclusions in the steel B are well dispersed, so these very small voids are created at various places in the work material. It causes the reduction of the cutting force.

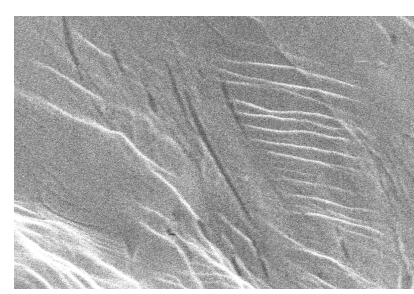

(a)

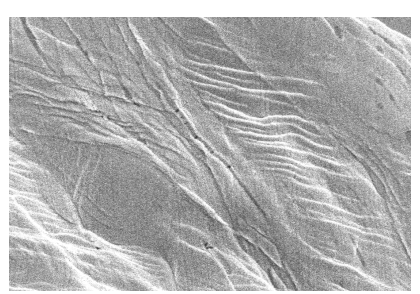

(b)

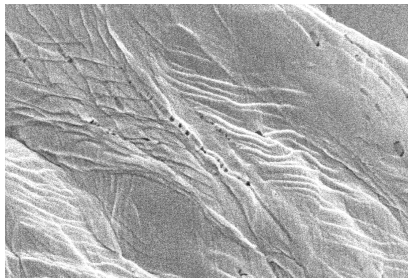

(c)

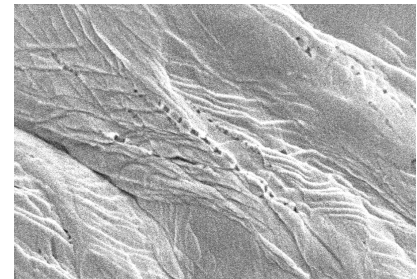

(d) $\quad 10 \underline{\mu m}$

Fig. 5 Deformation behavior of inclusion ( steel B )

Quick stop test during turning. A quick stop experiment during turning was done with the quick stop system which was attached to the lathe. The deformation behavior around the shear zone was observed. The cutting speed was $62 \mathrm{~m} / \mathrm{min}$ and the depth of cut was $0.2 \mathrm{~mm}$. Table 3 shows the cutting conditions. 
Table 3 Cutting condition in quick stop test

\begin{tabular}{|c|c|}
\hline Cutting speed & $62 \mathrm{~m} / \mathrm{min}$ \\
\hline Depth of cut & $0.2 \mathrm{~mm}$ \\
\hline Tool & Kyocera GH5020-02 KW-10 \\
\hline Rake angle & $20^{\circ}$ \\
\hline Clearance angle & $6^{\circ}$ \\
\hline
\end{tabular}

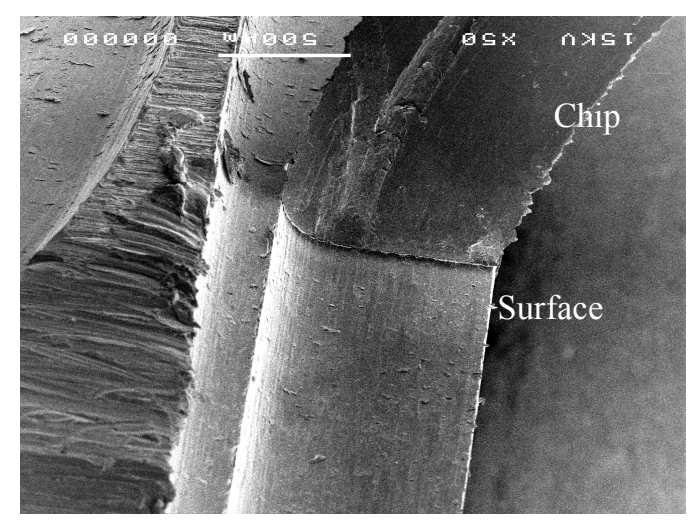

(a) Steel A
$500 \mu \mathrm{m}$

Fig. 6 Chip-surface in quick stop test

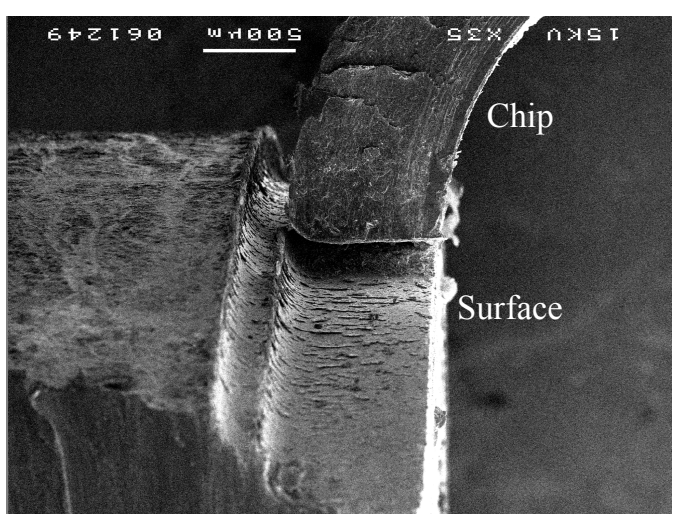

(b) Steel B

$500 \mu \mathrm{m}$

In quick stop test, the chips in the vicinity of the tool face and machined surface was observed as shown in Fig. 6. In case of steel A which contains large inclusions, the BUE could not be found. And machined surface had good surface roughness. In case of steel B which contains small inclusions, the BUE could be found on the rake face of the chip. There were many tears on the machined surface. The BUE partially separated and they leave on the machined surface. As a result, surface roughness became bad. In this experiment, it was clear that the larger inclusions can reduce the formation of BUE.

\section{Conclusions}

The main results obtained are as follows.

1) In machining of sulflized free-machining, some inclusions creates voids around them, some break to several pieces depending on their conditions around the shear zone.

2) The larger inclusions can reduce the formation of BUE.

\section{References}

[1] N. Narutaki, Y. Yamane, H. Usuki, B Yan, T. Kuwana: Journal of Japan Society for Precision Engineering vol.53, No.3 (1987) p.455 (in Japanese)

[2] H. Yaguchi: Iron and Steel vol.77, No.5 (1991) p.683 (in Japanese)

[3] E. Usui, T. Obikawa, T. Shirakashi: Japan Society for Precision Engineering vol.46, No.7 (1980) p.849 (in Japanese)

[4] T. Akazawa: Journal of Special Steel vol.46, No.5 (1997) p.6

[5] Araki, Yamamoto: Iron and Steel vol.57, No.3 (1971) p.1912 (in Japanese) 